\title{
Association of ApoE Genetic Polymorphism and Type 2 Diabetes with Cognition in Non-Demented Aging Chinese Adults: A Community Based Cross-Sectional Study
}

\author{
Jie Zhen, Tong Lin, Xiaochen Huang, Huiqiang Zhang, Shengqi Dong, Yifan Wu, Linlin Song, \\ Rong Xiao, Linhong Yuan*
}

School of Public Health, Capital Medical University, Beijing 100069, China

[Received May 31, 2017; Revised July 8, 2017; Accepted July 15, 2017]

\begin{abstract}
Apolipoprotein E (ApoE) gene polymorphism has been implicated in predisposition to diabetes and dementia in old population, but the results from the different studies were inconclusive. A cross-sectional study was carried out to explore the relationship among ApoE gene polymorphism, diabetes and cognition in non-demented aging Chinese adults. A total number of 1000 community dwellers aged 55 years and above were randomly recruited. Demographic information of the participants was collected using well designed selfadministered questionnaires. The Montreal Cognitive Assessment (MoCA) test was employed to evaluate the cognitive status of the participants. Semi-quantitative food frequency questionnaire was used to obtain the dietary intake information. Fasting venous blood samples were taken for ApoE genotyping and serum lipid measurements. 238 participants were type 2 diabetes mellitus (T2DM) patients and 145 participants were ApoE4 carriers. ApoE 4-T2DM subjects had higher serum triglyceride (TG) concentration than $E 2$ and $E 3$ carriers $(P$ $<0.05)$. T2DM subjects carrying ApoE4 had lower cognition than subjects with $E 2$ or $E 3$ carriers $(P<0.05)$. Comparing to non-type 2 diabetic mild cognitive impaired (nT2DM-MCI) subjects, the type 2 diabetic mild cognitive impaired (T2DM-MCI) subjects have higher serum glucose (Glu) level and lower high-density lipoprotein (HDL-C) level $(P<0.05)$. The T2DM-MCI subjects carrying ApoE4 have lower cognition than E2 and $E 3$ carriers $(P<0.05)$; and the interaction of $A p o E$ genotype with T2DM was detected $(P<0.05)$. Our results indicated the association among ApoE gene polymorphism, T2DM and cognitive performance in non-demented aging population. The carrying of ApoE4 predisposed the T2DM subjects and the T2DM-MCI subjects to have poor cognitive performance. Additional experimental studies are required to explore the mechanism that ApoE genotype modifies the risk for cognitive impairment in aging subjects with T2DM.
\end{abstract}

Key words: apolipoprotein E, polymorphism, type 2 diabetes mellitus, cognitive function, geriatrics

Type 2 diabetes mellitus (T2DM) is one of the most common chronic metabolic diseases throughout the world. It was estimated that more than 300 million people worldwide were affected by T2DM [1]. In 2010, the prevalence of T2DM was reported to be $11.6 \%$ in Chinese population [2]. Furthermore, the high incidence of Alzheimer's disease (AD) was observed in T2DM patients [3-5]. Epidemiology studies indicated that patients with T2DM had a 1.5-2.0-fold increased risk for developing dementia than those without T2DM [6,7]. T2DM, cognition decline and Alzheimer's disease (AD) are all age-associated progressive disability disorders with high prevalence in the elderly. The older population is growing dramatically in China. Therefore, in order to decrease the incidence of dementia in Chinese population, the prevention and control of T2DM are becoming much more urgent and imperative.

*Correspondence should be addressed to: Dr. Linhong Yuan, School of Public Health, Capital Medical University, Beijing. China. Email: ylhmedu@126.com

Copyright: ( 2017 Zhen J et al. This is an open-access article distributed under the terms of the Creative Commons Attribution License, which permits unrestricted use, distribution, and reproduction in any medium, provided the original author and source are credited. 
The underlying mechanisms through which that T2DM influencing cognitive functions in aging population are unclear [8]. Many factors such as gender, ethnicity and body weight were suggested to be associated with cognition changes in T2DM patients [9-11]. Additionally, as a typical diabetic phenotype, metabolic dyslipidemia was suggested to have strong correlation with cognition decline in aging subjects with diabetes [12]. Apolipoprotein E (ApoE) is a candidate gene for the development of T2DM due to its critical role in the lipid metabolism. Correlations between ApoE gene polymorphism and the pathogenesis of T2DM have been indicated in previous studies [13,14]. Besides, ApoE was proved to participate in the lipid metabolism and transport of cholesterol in brain [15]. Adverse associations of the ApoE \&4 allele have also been reported for the development of AD [16]. Earlier age of onset and a more rapid progression of the disease were usually founded in $\mathrm{AD}$ patients with ApoE $\& 4$ allele [17]. Data from experimental animal studies also indicated that the ApoE 4 isoform involved in the formation of $\beta$-amyloid $(\mathrm{A} \beta)$ plaques and neurofibrillary tangles (the two main neuropathological hallmarks of $\mathrm{AD}$ ) in the pathogenesis of $\mathrm{AD}$ [18]. Human beings-based studies indicated that the ApoE4 carrier exhibit reduced clearance of $A \beta$ and insufficient neuronal damage repair compared to the E2 and E3 carriers [19]. Recently, the increased risk for dementia in T2DM patients was also shown to be associated with ApoE genotypes [20]. T2DM patients carrying one or two $A p o E \& 4$ allele had a significantly higher risk of dementia than those who were negative for T2DM or ApoE \&4 allele [21].

Increased convincing evidences indicated the risk of cognitive impairment and AD in T2DM patients. Yet, the relationships between cognitive function and T2DM in non-demented elderly people remain insufficiently explored. ApoE gene polymorphisms have also been implicated in predisposition to diabetes and dementia, but the results from the different studies were inconclusive. Especially, few studies explore the association of ApoE genetic variants, T2DM with cognition in aging Chinese adults. Thus, in the present work, a community based cross-sectional study was carried out aiming to explore how ApoE gene polymorphism and T2DM associates with cognitive changes, as well as whether ApoE genetic polymorphism modulates the association between T2DM and cognitive function in non-demented community aging Chinese adults.

\section{MATERIALS AND METHODS}

\section{Participants}

A community-based cross-sectional study was carried out from April of 2012 to April of 2013. The design protocol was approved by the Human Ethics Committee of the Capital Medical University (No. 2012SY23). The procedures followed the ethical standards of the Helsinki Declaration of 1975. A total number of 1000 community dwellers aged 55 years and above were randomly recruited by advertisements and direct phone dialing by the nurses from Nanyuan and Wulituo Community service centers, Beijing, China. Subjects with conditions known to affect cognitive function (e.g., alcohol abuse, history of cerebral apoplexy or cerebral infarction); as well as subjects with $\mathrm{AD}$, Parkinson's disease (PD), long-term frequency intake of antidepressants and medication acting on central nervous system were also excluded from the present study. Diabetes was ascertained based on the selfreported medical history by the participants. Written informed consent was obtained from all enrolled participants.

\section{Socio-demographic Variables and Anthropometric Measurements}

Anthropometric measures, including height and weight, were documented by the nurses from the community medical service center. BMI was calculated as weight $(\mathrm{kg}) /$ height $\left(\mathrm{m}^{2}\right)$. Educational level was assessed as the highest level attained and classified into six categories (illiterate, primary school, junior high school, high school, junior college, undergraduate and above). Information on demographic characteristics (gender, age), lifestyle factors [e.g., smoking (yes or no), alcohol drinking (yes or no), physical activity (never, 1-3 times/wk, 4-5 times/wk, everyday)], living status (living alone, yes or no), reading habit (yes or no) and housework doing (yes or no) was collected by using a well structured self-administered questionnaire.

\section{Cognitive Test}

Global cognitive function was assessed with the Montreal Cognitive Assessment (MoCA) by medical doctors from the community health service center. MoCA test consists of seven cognitive domains including visual-spatial and executive ability, naming, attention, abstraction, language, delayed memory recall and orientation functions. The MoCA appears to have utility as a cognitive screening tool with high sensitivity and specificity for early detection of MCI $[22,23]$. According to previous study conducted in Chinese older population [24], the cut-off points used for mild cognitive impairment (MCI) diagnosis were as follow: 13/14 for individuals with no formal education, 19/20 for individuals with 1 to 6 years of education, and 24/25 for individuals with 7 or more years of education. The cut-offs above were proved 
sensitive and efficient in the diagnosis of MCI in older Chinese population.

\section{Dietary Assessment}

Participants were visited at a community health service center by specifically trained nutritionists and registered nurses. A validated semi-quantitative food frequency questionnaire (FFQ) was used to assess the habitual consumption of 10 food groups (fruit and vegetable, whole grain, legume, red meat, poultry, fish, eggs, nuts, cooking oil, milk, comprising 35 items in total). This questionnaire was adopted from a questionnaire used for the Dietary Investigation of Chinese Residents, which was organized by the Chinese Nutrition Society (CNS) [25]. The food intake survey documented the information, including the consumption frequencies (daily and weekly) and the amount of foods consumed.

\section{DNA Isolation and Genotyping}

Peripheral blood samples (6 $\mathrm{ml}$ intravenously) were collected in vacuum tubes and stored at $-80^{\circ} \mathrm{C}$. DNA was extracted from frozen peripheral blood using the Wizare genomic DNA purification kit (Promega, Madison, WI, USA). ApoE genotypes were determined by Polymerase Chain Reaction (PCR) amplification and Restricted Fragment Length Polymorphism (RFLP) analysis according to the method described by Hixson [24]. The specific primers used for $A p o E$ genotyping are: forward, 5'-GGC ACG GCT GTCCAA GGA-3'; reverse, 5'-GCC CCG GCC TGG TAC ACT GCC-3'. In addition, $20 \%$ of DNA samples were genotyped again by different operators for the purpose of quality control of the genotyping.

\section{Serum Parameter Measurement}

Blood samples were drawn after 12 hour (h) fasting. Then, centrifuged at $1500 \mathrm{~g}$ for 15 minutes at $4^{\circ} \mathrm{C}$, serum was separated within $2 \mathrm{~h}$, and all samples were stored at $40^{\circ} \mathrm{C}$ until further laboratory tests. An ILAB600 clinical chemistry analyzer (Instrumentation Laboratory, Lexington, WI, USA) was used to determine serum total cholesterol (TC) and triglyceride (TG). High density lipoprotein cholesterol (HDL-C) was measured by using a commercially available assay from Instrumentation Laboratory (Lexington, WI, USA). Low density lipoprotein cholesterol (LDL-C) was calculated by using the Friedewald formula [27]. All samples for each participant were analyzed within a single batch, and the inter-assay coefficients of variation $(\mathrm{CV})$ were less than $5 \%$.

\section{Statistical Analyses}

Data was analyzed with the software SPSS 19.0 (Chicago, IL, USA). Continuous variables were presented as mean (95\% confidence interval, CI) or means \pm standard deviation (SD). Gender, smoking, alcohol drinking, physical activity, living status, reading habit and housework doing were presented as category variables. Participants were classified according to categories of $A p o E$ alleles. General linear model (GLM) was used to compare the means of the detected parameters between the groups. The following putative confounding factors were included in the analyses: age, gender, body mass index (BMI), education level (schooling completed), physical activity (never, 1-3 times/week, 4-5 times/week, everyday), smoking (yes or no), alcohol drinking (yes or no), living status (living alone, yes or no), reading habit (yes or no) and housework doing (yes or no). $P<0.05$ was considered to be statistically significant.

\section{RESULTS}

\section{Demographics of the Participants}

Initially, a total of 1000 older Chinese adults participated in the present study. 48 subjects were excluded due to uncompleted questionnaires, unsuccessful biological specimen sampling or unsuccessful genotyping. A total of 952 participants were in the final sample analysis. For ApoE genotypes, subjects with the E2/E2 and E2/E3 genotypes were grouped as $E 2$ carrier; subjects with $E 3 / E 3$ were classified as $E 3$ homozygote; and subjects with $E 3 / E 4$ or $E 4 / E 4$ were grouped as $E 4$ carrier. $25.0 \%$ of the subjects were classified as having type 2 diabetes mellitus (T2DM); and $15.23 \%$ of the participants were ApoE4 carrier. There was no statistical significance of demographic factors including age, gender, BMI, education level and lifestyle between T2DM and nonT2DM (nT2DM) subjects $(P>0.05)$. Compared with subjects without T2DM, those with T2DM have higher serum Glu, TG levels and lower HDL-C level $(P<0.05)$. Of all T2DM subjects, $13.87 \%$ of the subjects were $E 4$ carriers. No statistical significance of $A p o E$ genotype frequencies and cognition was detected between nT2DM and T2DM subjects $(P>0.05)$ (Table $1 \& 2)$.

\section{Serum parameters and cognition by T2DM in MCI subjects}

Totally, 211 subjects were diagnosed as MCI according to the cut-off of MoCA score. And we categorized the MCI subjects into nT2DM-MCI group and T2DM-MCI group. As shown in Table 3, comparing to nT2DM-MCI subjects, the T2DM-MCI subjects have higher serum Glu level and lower HDL-C level $(P<0.05)$. No significant difference 
of $A p o E$ allele frequencies and cognition was detected between nT2DM and T2DM-MCI subjects $(P>0.05)$.

Table 1. Demographics of the participants.

\begin{tabular}{|c|c|c|c|c|}
\hline \multirow{2}{*}{ Demographic character } & \multicolumn{2}{|c|}{ T2DM } & \multirow{2}{*}{ Total $(n=952)$} & \multirow{2}{*}{$P$ value } \\
\hline & No $(n=714)$ & Yes $(n=238)$ & & \\
\hline $\begin{array}{l}\text { Age, mean } \pm \text { SD } \\
\text { Gender, } n(\%)\end{array}$ & $62.8 \pm 5.8$ & $63.2 \pm 5.7$ & $62.9 \pm 5.8$ & $\begin{array}{l}0.31 \\
0.17\end{array}$ \\
\hline male & $219(30.7)$ & $85(35.7)$ & $304(31.9)$ & \\
\hline Female & $495(69.3)$ & $153(64.3)$ & $648(68.1)$ & \\
\hline $\begin{array}{l}\text { BMI }\left(\mathrm{kg} / \mathrm{m}^{2}\right), \text { mean } \pm \text { SD } \\
\text { Education, } \mathrm{n}(\%)\end{array}$ & $25.5 \pm 7.6$ & $25.46 \pm 3.4$ & $25.5 \pm 6.8$ & $\begin{array}{l}0.87 \\
0.45\end{array}$ \\
\hline Illiterate & $23(3.2)$ & $12(5.0)$ & $35(3.7)$ & \\
\hline Primary school & $107(15.0)$ & $42(17.6)$ & $149(15.7)$ & \\
\hline Junior high school & $328(45.9)$ & $114(47.9)$ & $442(46.4)$ & \\
\hline High school & $190(26.6)$ & $53(22.3)$ & $243(25.5)$ & \\
\hline Junior college & $42(5.9)$ & $11(4.6)$ & $53(5.6)$ & \\
\hline \multicolumn{5}{|l|}{ Life style } \\
\hline Living alone, $\mathrm{n}(\%)$ & & & & 0.87 \\
\hline Yes & $44(6.2)$ & $13(5.5)$ & $57(6.0)$ & \\
\hline \multirow{2}{*}{ Smoking, n (\%) } & $670(93.8)$ & $225(94.5)$ & $895(94.0)$ & \\
\hline & & & & 0.24 \\
\hline Yes & $110(15.4)$ & $42(14.6)$ & $152(16.0)$ & \\
\hline No & $604(84.6)$ & $196(82.4)$ & $800(84.0)$ & \\
\hline Alcohol drinking, $\mathrm{n}(\%)$ & & & & 0.67 \\
\hline Yes & $199(27.9)$ & $63(26.5)$ & $262(27.5)$ & \\
\hline \multirow[b]{2}{*}{ Physical activity, n (\%) } & $501(72.1)$ & $175(73.5)$ & $690(72.5)$ & \\
\hline & & & & 0.14 \\
\hline Never & $73(10.2)$ & $25(10.5)$ & $98(10.3)$ & \\
\hline 1-3 times/week & $98(13.7)$ & $23(9.7)$ & $121(12.7)$ & \\
\hline 4-5 times/week & $91(12.8)$ & $22(9.2)$ & $113(11.9)$ & \\
\hline everyday & $451(63.2)$ & $168(70.6)$ & $619(65.1)$ & \\
\hline Reading habit, n (\%) & & & & 0.15 \\
\hline Yes & $342(47.9)$ & $100(42.0)$ & $442(46.4)$ & \\
\hline No & $372(52.1)$ & $138(58.0)$ & $510(53.6)$ & \\
\hline Housework doing, $\mathrm{n}(\%)$ & & & & 0.15 \\
\hline Yes & $676(94.7)$ & $220(92.4)$ & $896(94.3)$ & \\
\hline No & $38(5.3)$ & $18(7.6)$ & $56(5.9)$ & \\
\hline
\end{tabular}

Dietary intake of MCI subjects with or without T2DM

Dietary intake of nT2DM-MCI subjects and T2DM-MCI subjects were compared in Table 4 . We only detected the difference of daily legume intake between the groups ( $P$ $<0.05)$. For other food items, no statistical significance was observed between the groups $(P>0.05)$. 
Table 2. Serum parameter, ApoE genotype and cognition of the participants.

\begin{tabular}{|c|c|c|c|c|}
\hline \multirow{2}{*}{$\begin{array}{c}\text { Parameter, genotype and } \\
\text { cognition }\end{array}$} & \multicolumn{2}{|c|}{ T2DM } & \multirow{2}{*}{ Total $(n=952)$} & \multirow{2}{*}{$P$ value } \\
\hline & No $(n=714)$ & Yes $(n=238)$ & & \\
\hline \multicolumn{5}{|c|}{ Serum parameters $(\mathrm{mmol} / \mathrm{L})$, mean $(95 \% \mathrm{CI})$} \\
\hline Glu & $5.4(5.3,5.5)$ & $7.2(7.0,7.4)$ & $6.3(6.2,6.4)$ & 0.00 \\
\hline$T C$ & $5.1(5.0,5.2)$ & $5.0(4.8,5.1)$ & $5.0(5.0,5.1)$ & 0.12 \\
\hline$T G$ & $1.8(1.7,1.9)$ & $2.0(1.9,2.2)$ & $1.9(1.8,2.0)$ & 0.00 \\
\hline$L D L-C$ & $3.2(3.1,3.2)$ & $3.2(3.1,3.3)$ & $3.2(3.1,3.2)$ & 0.67 \\
\hline \multirow{2}{*}{ ApoE genotype, n (\%) } & $1.4(1.4,1.4)$ & $1.3(1.3,1.3)$ & $1.3(1.3,1.4)$ & 0.00 \\
\hline & & & & 0.68 \\
\hline$E 2$ & $105(14.7)$ & $29(12.2)$ & $134(14.1)$ & \\
\hline E3 & $497(69.6)$ & $176(74.0)$ & $673(70.7)$ & \\
\hline E4 & $112(15.7)$ & $33(13.9)$ & $145(15.2)$ & \\
\hline \multicolumn{5}{|l|}{ Cognition } \\
\hline Visual \& executive & $3.91(3.8,4.0)$ & $3.8(3.7,4.0)$ & $3.9(3.8,4.0)$ & 0.37 \\
\hline Naming & $2.9(2.9,2.9)$ & $2.9(2.9,3.0)$ & $2.9(2.8,2.9)$ & 0.91 \\
\hline Attention & $5.3(5.2,5.4)$ & $5.4(5.3,5.6)$ & $5.4(5.3,5.5)$ & 0.09 \\
\hline Language & $2.2(2.1,2.3)$ & $2.2(2.1,2.4)$ & $2.2(2.2,2.3)$ & 0.58 \\
\hline Abstraction & $1.6(1.5,1.7)$ & $1.6(1.5,1.7)$ & $1.6(1.6,1.7)$ & 0.69 \\
\hline Memory and delayed recall & $3.0(2.9,3.1)$ & $3.1(2.9,3.3)$ & $3.0(2.9,3.1)$ & 0.30 \\
\hline Orientation & $5.8(5.7,5.8)$ & $5.8(5.7,5.9)$ & $5.8(5.7,5.8)$ & 0.63 \\
\hline MoCA score & $24.9(24.5,25.2)$ & $25.2(24.6,25.8)$ & $25.1(24.7,25.4)$ & 0.29 \\
\hline \multicolumn{5}{|c|}{$\begin{array}{l}\text { Data were expressed as mean }(95 \% C I) \text {. Glu, glucose; HDL-C, high density lipoprotein cholesterol; LDL-C, low density } \\
\text { lipoprotein cholesterol; TC, total cholesterol; TG, triglyceride; ApoE, apolipoprotein E; T2DM: type } 2 \text { diabetes mellitus; MCI, } \\
\text { mild cognitive impairment. ApoE genotype frequencies were compared by using Chi-square test. General Line Model (GLM) } \\
\text { was used for data serum parameters and cognition comparison. During the comparison of serum parameters and cognition } \\
\text { between groups, factors including age, BMI, education, smoking, alcohol drinking, exercise, reading habits, housework doing } \\
\text { were adjusted. } P<0.05 \text { was considered as significance. }\end{array}$} \\
\hline
\end{tabular}

\section{Serum parameters and cognition by ApoE genotype in T2DM subjects}

As shown in Table 5, for serum TG concentration, the T2DM subjects carrying ApoE4 have higher serum TG concentration than ApoE2 carrier, and even higher than those with ApoE3 homozygote $(P<0.05)$. Cognition of the T2DM subjects was significantly different by $A p o E$ genotypes. The ApoE2-T2DM subjects had higher abstraction ability than subjects with ApoE3 homozygote, and much higher than $A p o E 4$ carrier $(P<0.05)$. For global cognition, the ApoE4-T2DM subjects had the lowest total MoCA score than ApoE2 carrier and those with ApoE3 homozygote $(P<0.05)$.

\section{Combine effect of ApoE genotype and T2DM on serum parameters and cognition in aging Chinese adults}

After grouping the participants according to ApoE genotype and whether they were T2DM patients, we did not detect the synergistic effect of $A p o E$ genotype and T2DM on serum parameter status and cognition $(P>0.05)$ (Table 6).

\section{Serum parameters and cognition by ApoE genotype in}

\section{T2DM-MCI subjects}

After grouping the T2DM-MCI subjects according to $A p o E$ genotypes, we observed significant difference of cognitive function by $A p o E$ genotypes. As shown in Table 7, comparing with $E 2$ and $E 3$ carriers, the $E 4$ subjects have lower cognitive abilities in visual \& executive, memory and delayed recall and orientation domains $(P<$ 0.05). Also, the global cognition (total MoCA score) of $A p o E 4$ carrier was lower than $E 2$ carriers and those with $E 3$ homozygote $(P<0.05)$. No difference of serum parameters by ApoE genotype was observed in T2DMMCI subjects $(P<0.05)$.

\section{Combine effect of ApoE genotype and T2DM on serum parameters and cognition in MCI subjects}

The combine effects of ApoE genotype and T2DM on serum parameters and cognition was detected in MCI subjects (Table 8). Among the MCI subjects, the lowest orientation ability and total MoCA score were observed in T2DM-MCI subjects carrying ApoE4; and the interaction of $A p o E$ genotype with T2DM was detected $(P<0.05)$. No combine effect of $A p o E$ genotype and T2DM on serum parameters in MCI subjects was observed $(P>0.05)$. 
Table 3. Serum parameters, ApoE genotype and cognition in MCI subjects with or without T2DM.

\begin{tabular}{|c|c|c|c|}
\hline Parameters, genotype and cognition & $\begin{array}{c}\text { nT2DM-MCI } \\
(n=168)\end{array}$ & $\begin{array}{c}\text { T2DM-MCI } \\
(n=43)\end{array}$ & $P$ value \\
\hline \multicolumn{4}{|l|}{ Serum Parameters (mmol/L) } \\
\hline (1) & $5.8(5.5,6.0)$ & $7.5(7.0,7.9)$ & 0.00 \\
\hline$T C$ & $5.3(5.1,5.5)$ & $5.2(4.8,5.5)$ & 0.61 \\
\hline$T G$ & $1.8(1.6,1.9)$ & $2.0(1.6,2.3)$ & 0.29 \\
\hline$L D L-C$ & $3.1(3.0,3.2)$ & $3.2(2.9,3.5)$ & 0.51 \\
\hline$H D L-C$ & $1.5(1.4,1.5)$ & $1.3(1.2,1.4)$ & 0.00 \\
\hline ApoE genotype, n (\%) & & & 0.81 \\
\hline 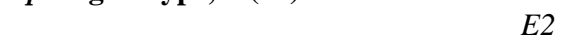 & $34(20.2)$ & $6(14.0)$ & \\
\hline$E 3$ & $111(66.1)$ & $31(72.1)$ & \\
\hline E4 & $23(13.7)$ & $6(14.0)$ & \\
\hline \multicolumn{4}{|l|}{ Cognition } \\
\hline Visual \& executive & $3.0(2.8,3.2)$ & $2.6(2.2,3.0)$ & 0.09 \\
\hline Naming & $2.7(2.6,2.8)$ & $2.6(2.4,2.9)$ & 0.61 \\
\hline Attention & $4.3(4.0,4.5)$ & $4.64 .1,5.1)$ & 0.27 \\
\hline Language & $1.3(1.2,1.5)$ & $1.6(1.4,1.9)$ & 0.07 \\
\hline Abstraction & $1.0(0.8,1.1)$ & $1.0(0.7,1.2)$ & 0.98 \\
\hline Memory and delayed recall & $1.5(1.3,1.7)$ & $1.5(1.0,1.9)$ & 0.88 \\
\hline Orientation & $5.3(5.0,5.5)$ & $5.3(4.9,5.8)$ & 0.78 \\
\hline MoCA score & $19.2(18.3,20.1)$ & $19.4(17.5,21.2)$ & 0.86 \\
\hline
\end{tabular}

Data were expressed as mean $(95 \% C I)$. Glu, glucose; HDL-C, high density lipoprotein cholesterol; LDL-C, low density lipoprotein cholesterol; TC, total cholesterol; TG, triglyceride; ApoE, apolipoprotein E; T2DM: type 2 diabetes mellitus; MCI, mild cognitive impairment. ApoE genotype frequencies were compared by using Chi-square test. General Line Model (GLM) was used for data serum parameters and cognition comparison. During the comparison of serum parameters and cognition between groups, factors including age, BMI, education, smoking, alcohol drinking, exercise, reading habits, housework doing were adjusted. $P<0.05$ was considered as significance.

Table 4. Dietary intake of MCI subjects with or without T2DM.

\begin{tabular}{lccc}
\hline \multicolumn{1}{c}{ Foods $(\mathbf{g} / \mathbf{d})$} & $\begin{array}{c}\text { nT2DM-MCI } \\
(\boldsymbol{n}=\mathbf{1 6 8})\end{array}$ & $\begin{array}{c}\text { T2DM-MCI } \\
(\boldsymbol{n}=\mathbf{4 3})\end{array}$ & $\boldsymbol{P}$ value \\
& & & 0.06 \\
\hline Fruit & $154.5(139.2,169.8)$ & $121.4(90.3,152.6)$ & 0.58 \\
Vegetable & $289.8(270.1,309.4)$ & $277.2(237.2,317.2)$ & 0.14 \\
Fruit + Vegetable & $444.3(417.7,470.8)$ & $398.6(344.6,452.7)$ & 0.02 \\
legume & $29.0(25.2,32.8)$ & $18.65(10.9,26.4)$ & 0.85 \\
Cooking oil & $30.6(28.0,33.2)$ & $31.18(25.9,36.4)$ & 0.41 \\
Fish & $19.4(17.2,21.6)$ & $17.31(12.8,21.8)$ & 0.61 \\
Whole grain & $27.7(24.9,30.4)$ & $26.1(20.5,31.6)$ & 0.16 \\
Red meat & $27.9(24.0,31.8)$ & $21.5(13.5,29.5)$ & 0.47 \\
Poultry & $13.3(11.2,15.4)$ & $10.6(5.2,15.8)$ & 0.62 \\
Nut & $12.7(10.4,15.0)$ & $200.8(168.6,232.9)$ & 0.52 \\
Milk & $191.5(175.8,207.3)$ & $32.1(27.0,37.2)$ & \\
Egg & $30.2(27.7,32.7)$ & \\
\hline Data were expressed as mean $(95 \%$ CI). nT2DM-MCI: mild cognitive impairment subjects without type 2 diabetes mellitus; \\
T2DM-MCI: mild cognitive impairment subjects with type 2 diabetes mellitus. General Line Model (GLM) was used for data \\
analysis. Factors including sex, age, BMI and exercise were adjusted. $P<0.05$ was considered as significance.
\end{tabular}


Table 5. Serum parameters and cognition according to ApoE genotype in T2DM patients.

\begin{tabular}{|c|c|c|c|c|}
\hline $\begin{array}{l}\text { Serum parameters and } \\
\text { cognition }\end{array}$ & ApoE E2 $(n=29)$ & $\operatorname{ApoE3}(n=176)$ & $\operatorname{ApoE4}(n=33)$ & $P$ value \\
\hline \multicolumn{5}{|l|}{$\begin{array}{l}\text { Serum Parameters } \\
(\mathrm{mmol} / \mathrm{L})\end{array}$} \\
\hline Glu & $7.2(6.3,8.1)$ & $7.2(6.8,7.6)$ & $7.3(6.4,8.2)$ & 0.98 \\
\hline$T C$ & $5.0(4.5,5.4)$ & $4.9(4.7,5.0)$ & $4.9(4.5,5.3)$ & 0.35 \\
\hline$T G$ & $2.5(1.8,3.1)$ & $1.8(1.6,2.1)$ & $2.6(2.0,3.2)$ & 0.04 \\
\hline$L D L-C$ & $2.9(2.5,3.3)$ & $3.2(3.0,3.3)$ & $3.1(2.7,3.4)$ & 0.40 \\
\hline$H D L-C$ & $1.3(1.1,1.4)$ & $1.3(1.3,1.4)$ & $1.2(1.1,1.3)$ & 0.44 \\
\hline \multicolumn{5}{|l|}{ Cognition } \\
\hline Visual \& executive & $3.9(3.2,4.5)$ & $3.7(3.2,4.1)$ & $3.3(2.9,3.8)$ & 0.10 \\
\hline Naming & $2.9(2.7,3.2)$ & $2.9(2.9,3.0)$ & $2.8(2.6,2.9)$ & 0.14 \\
\hline Attention & $5.5(5.1,5.9)$ & $5.4(5.2,5.6)$ & $5.2(4.8,5.6)$ & 0.73 \\
\hline Language & $2.4(2.1,2.7)$ & $2.2(2.1,2.4)$ & $1.9(1.6,2.2)$ & 0.08 \\
\hline Abstraction & $1.7(1.5,2.0)$ & $1.6(1.5,1.8)$ & $1.6(1.4,1.9)$ & 0.01 \\
\hline Memory and delayed recall & $2.7(2.2,3.3)$ & $3.2(2.9,3.4)$ & $2.9(2.4,3.5)$ & 0.12 \\
\hline Orientation & $5.8(5.6,6.1)$ & $5.8(5.7,5.9)$ & $5.54(5.3,5.8)$ & 0.24 \\
\hline MoCA score & $25.2(23.6,26.8)$ & $25.5(24.8,26.1)$ & $23.6(22.1,25.0)$ & 0.04 \\
\hline
\end{tabular}

\section{DISCUSSION}

Higher MCI prevalence was observed in T2DM patients than in the general population [28, 29]. Patients with both T2DM and MCI had a faster cognitive deterioration process than patients with MCI only [30]. All these data indicated that T2DM is a risk factor for the old population to have cognition decline. In the present study, we carried out a community based cross-sectional study trying to explore the association of ApoE genetic polymorphism, T2DM and cognition in non-demented aging Chinese adults. In the present study, we detected the $A p o E$ genotype difference of cognitive performance in subjects with T2DM. The ApoE4-T2DM subjects have the lowest cognition as comparing with T2DM subjects carrying E2 or E3. Moreover, the carrying of ApoE4 predisposed the
T2DM-MCI subjects to have much poor cognitive performance.

Cognition and serum parameter levels were compared between the T2DM and nT2DM subjects. Our data did not implicate obvious difference of cognitive function between theT2DM and nT2DM subjects $(P>0.05)$ (Table $1 \& 2)$. This result was not in agreement with some previous studies [31,32]. Except of differences in study design and the method used for assessing cognitive function, the discrepancies between our and others' studies might result from the inclusion of participants (all participants in the present study were community dwellers without clinically diagnosable cognition decline or dementia).

It is well known that glucose metabolism disorder (hyperglycemia) was the typical diabetic phenotype of T2DM patients. Hyperglycemia was suggested one of the 
mechanisms contributing to the cognition decline in diabetes. Chronic exposure to high levels of glucose could cause selective death of neurons, which terminally leads to cognitive deficits [33]. Abnormal lipid profile in T2DM patients was also implicated by previous studies [34,35]. Windler and Taskinen also reported that, compared to nT2DM individuals, markedly higher triglycerides and moderately lower HDL levels were detected in the diabetes patients [36,37]. In the current study, notable difference of serum Glu, TG and HDL-C levels were observed among participants with and without diabetes $(P$ $<0.05)$. The largest disparity in serum glucose and lipid levels observed in T2DM and nT2DM subjects indicating the impaired of glucose and lipids metabolism in T2DM subjects. The serum parameter levels and cognition in MCI subjects with or without T2DM were also compared (Table 3). Although, no statistical significant difference of cognition by T2DM was observed, we founded that the serum lipid profile was obviously difference between the T2DM-MCI and nT2DM-MCI subjects. The T2DM-MCI subjects had higher serum Glu level and lower HDL-C level than nT2DM-MCI subjects $(P<0.05)$. According

Table 6. Combine effect of ApoE genotype and T2DM on serum parameters and cognition in aging Chinese subjects.

\begin{tabular}{|c|c|c|c|c|c|c|c|}
\hline \multirow{2}{*}{$\begin{array}{c}\text { Serum } \\
\text { parameters } \\
\text { and cognition }\end{array}$} & \multicolumn{2}{|c|}{ ApoE2 $(n=134)$} & \multicolumn{2}{|c|}{$\operatorname{ApoE3}(n=673)$} & \multicolumn{2}{|c|}{ ApoE4 $(\mathrm{n}=145)$} & \multirow{2}{*}{$P$ value } \\
\hline & $\begin{array}{l}\text { nT2DM } \\
(n=105)\end{array}$ & $\begin{array}{l}\text { T2DM } \\
(n=29)\end{array}$ & $\begin{array}{l}\text { nT2DM } \\
(n=497)\end{array}$ & $\begin{array}{c}\text { T2DM } \\
(n=176)\end{array}$ & $\begin{array}{l}\text { nT2DM } \\
(n=112)\end{array}$ & $\begin{array}{l}\text { T2DM } \\
(n=33) \\
\end{array}$ & \\
\hline \multicolumn{8}{|c|}{ Serum parameter $(\mathrm{mmol} / \mathrm{L})$} \\
\hline Glu & $5.5(5.2,5.9)$ & $7.3(6.7,7.9)$ & $5.4(5.2,5.5)$ & $7.2(7.0,7.5)$ & $5.2(4.9,5.6)$ & $7.3(6.7,8.0)$ & 0.30 \\
\hline$T C$ & $5.2(4.9,5.4)$ & $5.0(4.6,5.4)$ & $5.0(4.9,5.1)$ & $4.9(4.7,5.1)$ & $5.2(5.0,5.4)$ & $5.0(4.6,5.4)$ & 0.97 \\
\hline$T G$ & $2.2(1.9,2.5)$ & $2.6(2.0,3.07)$ & $1.7(1.5,1.8)$ & $1.9(1.6,2.1)$ & $1.8(1.5,2.0)$ & $2.6(2.1,3.1)$ & 0.21 \\
\hline$L D L-C$ & $2.9(2.7,3.1)$ & $2.9(2.6,3.3)$ & $3.2(3.1,3.3)$ & $3.2(3.1,3.3)$ & $3.3(3.1,3.5)$ & $3.1(2.8,3.4)$ & 0.55 \\
\hline$H D L-C$ & $1.5(1.4,1.6)$ & $1.3(1.1,1.4)$ & $1.4(1.3,1.4)$ & $1.3(1.3,1.4)$ & $1.4(1.4,1.5)$ & $1.2(1.1,1.3)$ & 0.05 \\
\hline \multicolumn{8}{|l|}{ Cognition } \\
\hline $\begin{array}{l}\text { Visual \& } \\
\text { executive }\end{array}$ & $3.8(3.6,4.1)$ & $3.6(3.2,4.1)$ & $3.9(3.8,4.0)$ & $4.0(3.8,4.1)$ & $4.0(3.7,4.2)$ & $3.4(3.0,3.8)$ & 0.14 \\
\hline Naming & $2.9(2.8,3.0)$ & $2.9(2.7,3.0)$ & $2.9(2.9,3.0)$ & $2.9(2.9,3.0)$ & $2.8(2.8,2.9)$ & $2.8(2.6,2.9)$ & 0.63 \\
\hline Attention & $5.2(4.9,5.4)$ & $5.5(5.1,6.0)$ & $5.3(5.2,5.4)$ & $5.5(5.3,5.6)$ & $5.4(5.2,5.6)$ & $5.2(4.8,5.6)$ & 0.46 \\
\hline Language & $2.1(1.9,2.3)$ & $2.4(2.1,2.7)$ & $2.2(2.2,2.3)$ & $2.3(2.1,2.4)$ & $2.2(2.0,2.3)$ & $2.0(1.7,2.3)$ & 0.24 \\
\hline Abstraction & $1.6(1.4,1.7)$ & $1.8(1.5,2.0)$ & $1.7(1.6,1.7)$ & $1.7(1.5,1.8)$ & $1.6(1.5,1.7)$ & $1.6(1.4,1.8)$ & 0.64 \\
\hline $\begin{array}{l}\text { Memory and } \\
\text { delayed recall }\end{array}$ & $3.1(2.8,3.4)$ & $2.7(2.2,3.3)$ & $3.1(2.9,3.2)$ & $3.2(3.0,3.4)$ & $3.0(2.7,3.3)$ & $3.0(2.5,3.5)$ & 0.42 \\
\hline orientation & $5.8(5.6,5.9)$ & $5.9(5.6,6.18)$ & $5.8(5.7,5.9)$ & $5.9(5.7,6.0)$ & $5.7(5.6,5.9)$ & $5.5(5.2,5.8)$ & 0.48 \\
\hline MoCA score & $24.5(23.6,25.4)$ & $25.3(23.5,27.0)$ & $25.1(24.7,25.5)$ & $25.7(25.0,26.4)$ & $24.9(24.0,25.8)$ & $23.7(22.1,25.3)$ & 0.38 \\
\hline
\end{tabular}

to previous study, a higher prevalence of T2DM or impaired glucose metabolism in patients with AD than in control subjects [38], which supports the involvement of impaired glucose metabolism in AD development. Regarding serum lipid profile, it was efficiency influenced by dietary fat-containing foods intakes. Thus, the comparison of dietary intakes of fat-containing foods between T2DM-MCI and nT2DM-MCI subjects might help us to uncover the underlying mechanism contributing to the observed inconsistency of serum lipid profile. No significant difference of dietary fat-containing foods intake was founded between T2DM-MCI and nT2DMMCI subjects $(P>0.05)$. Our data only implicated the relative lower legume (a protein rich food) intake in T2DM-MCI subjects than nT2DM MCI subjects (Table 4). This result indicated that, except of diet, some other factors might contribute to the significant different lipid profile between T2DM-MCI and nT2DM-MCI subjects. 
Table 7. Serum parameters and cognition according to ApoE genotype in T2DM-MCI subjects.

\begin{tabular}{|c|c|c|c|c|}
\hline $\begin{array}{l}\text { Serum parameters and } \\
\text { cognition }\end{array}$ & $\operatorname{ApoE2}(n=6)$ & $\operatorname{ApoE3}(n=31)$ & $\operatorname{ApoE4}(n=6)$ & $P$ value \\
\hline \multicolumn{5}{|l|}{ Serum Parameters $(\mathbf{m m o l} / \mathrm{L})$} \\
\hline Glu & $6.7(4.8,8.6)$ & $7.5(6.7,8.3)$ & $8.9(6.9,11.0)$ & 0.43 \\
\hline$T C$ & $4.7(3.5,5.9)$ & $5.0(4.5,5.5)$ & $5.5(4.2,6.8)$ & 0.53 \\
\hline$T G$ & $1.6(0.2,3.0)$ & $2.2(1.6,2.8)$ & $1.9(0.4,3.4)$ & 0.57 \\
\hline$L D L-C$ & $2.4(1.3,3.5)$ & $3.1(2.7,3.6)$ & $3.2(2.0,4.3)$ & 0.36 \\
\hline$H D L-C$ & $1.4(1.2,1.7)$ & $1.2(1.1,1.3)$ & $1.1(0.9,1.4)$ & 0.25 \\
\hline \multicolumn{5}{|l|}{ Cognition } \\
\hline Visual \& executive & $2.6(1.4,3.8)$ & $2.6(2.1,3.1)$ & $0.6(-0.6,1.9)$ & 0.01 \\
\hline Naming & $2.8(2.1,3.5)$ & $2.8(2.5,3.1)$ & $1.6(0.9,2.4)$ & 0.06 \\
\hline Attention & $4.2(2.7,5.8)$ & $4.6(3.9,5.2)$ & $3.2(1.6,4.8)$ & 0.42 \\
\hline Language & $2.2(1.3,3.1)$ & $1.7(1.3,2.0)$ & $0.5(-0.5,1.4)$ & 0.09 \\
\hline Abstraction & $0.8(0.0,1.6)$ & $1.2(0.9,1.5)$ & $0.2(-0.6,1.1)$ & 0.07 \\
\hline Memory and delayed recall & $0.5(-0.1,1.9)$ & $1.9(1.3,2.4)$ & $0.2(-1.1,1.6)$ & 0.04 \\
\hline Orientation & $5.3(4.2,6.4)$ & $5.6(5.1,6.0)$ & $3.6(2.4,4.7)$ & 0.02 \\
\hline MoCA score & $18.1(13.2,23.0)$ & $20.5(18.5,22.5)$ & $10.5(5.3,15.6)$ & 0.01 \\
\hline
\end{tabular}

Data were expressed as mean $(95 \% \mathrm{Cl})$. ApoE: apolipoprotein E. General Line Model (GLM) was used for data serum parameters and cognition comparison. During the comparison of serum parameters and cognition between groups, factors including age, BMI, education, smoking, alcohol drinking, exercise, reading habits, housework doing were adjusted. $P<0.05$ was considered as significance; and $P$ value stand for the statistical significance between different $A p o E$ genotype groups.

$A p o E \varepsilon 4$ is an established risk factor for late-onset Alzheimer's disease. Moreover, the development of T2DM was suggested to be associated with ApoE genotype [39]. Therefore, in the current study, we try to explore whether there was synergistic effect of $A p o E$ genotype and T2DM on cognition in non-demented aging adults. Although the combine effect of ApoE genotype with T2DM in affecting cognitive function and serum parameters was not observed, we founded that serum TG level and several cognitive domains (including abstraction domain and global cognition) in T2DM subjects were associated with ApoE genotype. As comparing with nT2DM subjects, higher serum TG level was detected in T2DM subjects carrying ApoE4 or ApoE2, which implicating the susceptibility of serum TG concentration to genetic variant of $A p o E$ in T2DM patients. Moreover, for ApoE4-T2DM subjects, the effect of ApoE on serum TG status became more remarkable (Table 5). Our results are consistent with the study carried out in Thai population. In which, the researcher founded that $A p o E \varepsilon 4$ allele-diabetic carriers showed a significantly higher serum TG and lower HDL-C levels compared to E3/E3 genotype carriers [40]. Additionally, ApoE $\varepsilon 4$ allele was also reported to be associated with higher serum LDL-C and lower HDL-C levels in Spanish with T2DM [41]. Totally, these results suggested that, for T2DM subjects, the carrying of $A p o E \& 4$ allele implicate a predisposition of lipid metabolism disorder and cognition decline. 
Table 8. Combine effect of $A p o E$ genotype and T2DM on serum parameters and cognition in MCI subjects,

\begin{tabular}{|c|c|c|c|c|c|c|c|}
\hline \multirow[b]{2}{*}{$\begin{array}{l}\text { Parameters } \\
\text { and cognition }\end{array}$} & \multicolumn{2}{|c|}{$\operatorname{ApoE2}(n=40)$} & \multicolumn{2}{|c|}{$\operatorname{ApoE3}(n=142)$} & \multicolumn{2}{|c|}{ ApoE4 $(n=29)$} & \multirow[b]{2}{*}{$\begin{array}{c}P \\
\text { value }\end{array}$} \\
\hline & $\begin{array}{c}\text { nT2DM-MCI } \\
(n=34)\end{array}$ & $\begin{array}{c}\text { T2DM-MCI } \\
(n=6)\end{array}$ & $\begin{array}{c}\text { nT2DM-MCI } \\
(n=111)\end{array}$ & $\begin{array}{c}\text { T2DM-MCI } \\
(n=31)\end{array}$ & $\begin{array}{c}\text { nT2DM-MCI } \\
(n=23)\end{array}$ & $\begin{array}{c}\text { T2DM-MCI } \\
(n=6)\end{array}$ & \\
\hline \multicolumn{8}{|c|}{ Serum parameters $(\mathrm{mmol} / \mathrm{L})$} \\
\hline Glu & $5.8(5.2,6.4)$ & $6.7(4.8,8.6)$ & $5.6(5.3,5.9)$ & $7.5(6.7,8.3)$ & $5.8(5.1,6.5)$ & $8.9(6.9,11.0)$ & 0.37 \\
\hline$T C$ & $5.5(5.1,5.9)$ & $4.7(3.5,5.9)$ & $5.1(4.9,5.4)$ & $5.0(4.5,5.5)$ & $5.9(5.3,6.4)$ & $5.5(4.2,6.8)$ & 0.29 \\
\hline$T G$ & $2.0(1.6,2.5)$ & $1.6(0.2,3.0)$ & $1.6(1.4,1.8)$ & $2.2(1.6,2.8)$ & $1.9(1.4,2.5)$ & $1.9(0.4,3.4)$ & 0.14 \\
\hline$L D L-C$ & $2.9(2.6,3.3)$ & $2.4(1.3,3.5)$ & $3.1(2.9,3.3)$ & $3.1(2.7,3.6)$ & $3.4(3.0,3.9)$ & $3.2(2.0,4.3)$ & 0.14 \\
\hline$H D L-C$ & $1.6(1.5,1.7)$ & $1.4(1.2,1.7)$ & $1.6(1.5,1.7)$ & $1.2(1.1,1.3)$ & $1.4(1.4,1.5)$ & $1.1(0.9,1.4)$ & 0.87 \\
\hline \multicolumn{8}{|l|}{ Cognition } \\
\hline $\begin{array}{l}\text { Visual \& } \\
\text { executive }\end{array}$ & $3.3(2.8,3.8)$ & $2.6(1.4,3.8)$ & $3.0(2.7,3.3)$ & $2.6(2.1,3.1)$ & $2.7(2.1,3.3)$ & $0.6(-0.6,1.9)$ & 0.09 \\
\hline Naming & $2.8(2.5,3.0)$ & $2.8(2.1,3.5)$ & $2.8(2.6,2.9)$ & $2.8(2.5,3.1)$ & $2.3(1.9,2.6)$ & $1.6(0.9,2.4)$ & 0.18 \\
\hline Attention & $4.4(3.8,5.0)$ & $4.3(2.7,5.8)$ & $4.2(3.8,4.5)$ & $4.6(3.9,5.2)$ & $3.9(3.2,4.6)$ & $3.2(1.6,4.8)$ & 0.39 \\
\hline Language & $1.3(1.1,1.7)$ & $2.2(1.3,3.1)$ & $1.3(1.1,1.5)$ & $1.7(1.3,2.0)$ & $1.1(0.8,1.5)$ & $0.5(-0.5,1.4)$ & 0.06 \\
\hline Abstraction & $0.8(0.5,1.1)$ & $0.8(0.0,1.6)$ & $1.1(0.9,1.3)$ & $1.2(0.9,1.5)$ & $0.9(0.5,1.2)$ & $0.2(-0.6,1.1)$ & 0.32 \\
\hline $\begin{array}{l}\text { Memory and } \\
\text { delayed recall }\end{array}$ & $1.6(1.2,2.1)$ & $0.5(-1.0,1.9)$ & $1.6(1.3,1.8)$ & $1.7(1.3,2.4)$ & $1.6(1.0,2.2)$ & $0.2(-1.1,1.6)$ & 0.20 \\
\hline orientation & $5.2(4.7,5.8)$ & $5.3(4.2,6.4)$ & $5.2(4.9,5.5)$ & $5.6(5.1,6.0)$ & $5.0(4.4,5.6)$ & $3.6(2.4,4.7)^{*}$ & 0.01 \\
\hline MoCA score & $19.6(17.5,21.7)$ & $18.1(13.2,23.0)$ & $19.3(18.1,20.5)$ & $20.5(18.5,22.5)$ & $17.6(15.0,20.1)$ & $10.5(5.3,15.1) *$ & 0.03 \\
\hline
\end{tabular}

Data were expressed as mean $(95 \% \mathrm{CI})$. ApoE: apolipoprotein E; nT2DM-MCI, mild cognitive impairment subjects without type 2 diabetes mellitus; T2DM-MCI, mild cognitive impairment subjects with type 2 diabetes mellitus. General Line Model (GLM) was used for data serum parameters and cognition comparison. During the comparison of serum parameters and cognition between groups, factors including age, BMI, education, smoking, alcohol drinking, exercise, reading habits, housework doing were adjusted. $P<0.05$ was considered as significance; $P$ value stands for the statistical significance of $A p o E$ genotype and T2DM interaction. *: $P<0.05$, comparing with other nT2DM or T2DM MCI subjects with different $A p o E$ genotypes.

After grouping the T2DM-MCI subjects by ApoE genotype, we observed notable difference of cognition between groups. Previous researches have indicated that diabetes is related to decrements in several cognitive domains, including processing speed, executive functions and memory [42-44]. In the present study, the cognition of ApoE4 carriers were characterized as much lower abilities in visual \& executive, memory and delayed recall and orientation domains accompanying with decreased global cognition (total MoCA score) than subjects with other ApoE genotypes (Table 7). Additionally, the interaction of $A p o E$ genotype and T2DM on cognition (especially on the orientation domain and global cognition) was detected (Table 8). Our findings suggest that T2DM might involve in cognitive change in an $A p o E$ genotype-dependent way. The carrying of ApoE $\varepsilon 4$ allele might expose the T2DM subjects to the high risk of cognition decline. These findings were partially in line with previous studies. Increasing evidences indicated that T2DM have been associated with accelerated cognitive decline, and dementia among older adults [45]. Additionally, it was reported that T2DM and ApoE $\varepsilon 4$ allele synergistically increased the pathological changes, such as neuritic plaques in hippocampus, NFTs in the cortex and hippocampus, and amyloid angiopathy in the brain [46]. These results indicated that ApoE gene polymorphism might be associated with a wide range of pathophysiological changes in brain and terminally affecting the cognitive functional status in T2DM patients.

Some limitations of the present study should also be addressed. The relative small sample size is a major 
drawback of the current study, so the extrapolation of our results to others should be with caution. Moreover, the current study was a community-based cross-sectional study, lacking the capacity of causal inference. Although some covariates were adjusted during the data analysis, some residual confounding is possible. Without measuring T2DM and cognition related biomarkers, we are incapable to exploring the interactive mechanism underlying ApoE genotype, T2DM and cognition. Although these shortcomings, our results, combined with those from other studies, suggested that older individuals with T2DM and ApoE $\varepsilon 4$ allele are at an increased risk of cognition decline. Additional experimental studies are required to test the hypothesis that ApoE genotype modifies the risk for cognitive impairment in aging subjects with T2DM.

\section{Conclusion}

In summary, our data implicated the association among ApoE gene polymorphism, T2DM and cognition in nondemented aging Chinese adults. The ApoE4-T2DM subjects and ApoE4-T2DM-MCI subjects were predisposed to have poor cognitive performance. In the future, long time cohort studies were needed with regard to how genetic background modulates the association between diabetes and cognitive function in aging population. The precise biological mechanism underlying this significant association should be investigated.

\section{Acknowledgment}

The authors thank all study participants for their participation. This study was supported by the grants from National Natural Science Foundation of China (No. 81673148; No. 81273071) and 2015 Chinese Nutrition Society (CNS) Nutrition Research Foundation-DSM Research Fund (CNS2015070B).

\section{References}

[1] Rivillas-Acevedo L, Sanchez-Lopez C, Amero C, Quintanar L (2015). Structural basis for the inhibition of truncated islet amyloid polypeptide aggregation by $\mathrm{cu}$ (ii): Insights into the bioinorganic chemistry of type ii diabetes. Inorg Chem, 54:3788-96.

[2] Xu Y, Wang L, He J, Bi Y, Li M, Wang T, Wang L, Jiang Y, Dai M, Lu J, Xu M, Li Y, Hu N, Li J, Mi S, Chen CS, Li G, Mu Y, Zhao J, Kong L, Chen J, Lai S, Wang W, Zhao W, Ning G (2013). Prevalence and control of diabetes in Chinese adults. JAMA, 310: 948-59.

[3] Leibson CL, Rocca WA, Hanson VA, Cha R, Kokmen E, O'Brien PC, Palumbo PJ (1997). The risk of dementia among persons with diabetes mellitus: A population- based cohort study. Ann N Y Acad Sci, 826: 422-7.

[4] Brayne C, Gill C, Huppert FA, Barkley C, Gehlhaar E, Girling DM, O'Connor DW, Paykel ES (1998). Vascular risks and incident dementia: Results from a cohort study of the very old. Dement Geriatr Cogn Disord, 9:175-80.

[5] Irie F, Fitzpatrick AL, Lopez OL, Kuller LH, Peila R, Newman AB, Launer LJ (2008). Enhanced risk for Alzheimer disease in persons with type 2 diabetes and apoe epsilon4: The cardiovascular health study cognition study. Arch Neurol, 65:89-93.

[6] Cheng PY, Sy HN, Wu SL, Wang WF, Chen YY (2012). Newly diagnosed type 2 diabetes and risk of dementia: A population-based 7-year follow-up study in Taiwan. $\mathbf{J}$ Diabetes Complications, 26:382-7.

[7] Strachan MW, Reynolds RM, Marioni RE, Price JF (2011). Cognitive function, dementia and type 2 diabetes mellitus in the elderly. Nat Rev Endocrinol, 7:108-14.

[8] Zhao WQ, Townsend M (2009). Insulin resistance and amyloidogenesis as common molecular foundation for type 2 diabetes and Alzheimer's disease. Biochim Biophys Acta, 1792:482-96.

[9] Lin CH, Sheu WH (2013). Hypoglycaemic episodes and risk of dementia in diabetes mellitus: 7-year follow-up study. J Intern Med, 273:102-10.

[10] West RK, Ravona-Springer R, Heymann A, Schmeidler J, Leroith D, Koifman K, Guerrero-Berroa E, Preiss R, Hoffman H, Silverman JM, Beeri MS (2015). Shorter adult height is associated with poorer cognitive performance in elderly men with type ii diabetes. J Alzheimers Dis, 44:927-35.

[11] Mayeda ER, Haan MN, Neuhaus J, Yaffe K, Knopman DS, Sharrett AR, Griswold ME, Mosley TH (2014). Type 2 diabetes and cognitive decline over 14 years in middle-aged african americans and whites: The aric brain mri study. Neuroepidemiology, 43:220-7.

[12] Sijbrands EJ, Westendorp RG, Hoffer MJ, Havekes LM, Frants RR, Meinders AE, Frolich M, Smelt AH (1994). Effect of insulin resistance, apoe 2 allele, and smoking on combined hyperlipidemia. Arterioscler Thromb, 14:1576-80.

[13] Anthopoulos PG, Hamodrakas SJ, Bagos PG (2010). Apolipoprotein e polymorphisms and type 2 diabetes: A meta-analysis of 30 studies including 5423 cases and 8197 controls. Mol Genet Metab, 100: 283-91.

[14] Messier C (2003). Diabetes, Alzheimer's disease and apolipoprotein genotype. Exp Gerontol, 38: 941-6.

[15] Schipper HM (2011). Apolipoprotein e: Implications for ad neurobiology, epidemiology and risk assessment. Neurobiol Aging, 32:778-90.

[16] Farrer LA, Cupples LA, Haines JL, Hyman B, Kukull WA, Mayeux R, Myers RH, Pericak-Vance MA, Risch N, van Duijn CM (1997). Effects of age, sex, and ethnicity on the association between apolipoprotein e genotype and alzheimer disease. A meta-analysis. Apoe and Alzheimer disease Meta analysis consortium. JAMA, 278:1349-56.

[17] Corder EH, Saunders AM, Strittmatter WJ, Schmechel DE, Gaskell PC, Small GW, Roses AD, Haines JL, Pericak-Vance MA (1993). Gene dose of apolipoprotein 
e type 4 allele and the risk of Alzheimer's disease in late onset families. Science, 261: 921-3.

[18] Nagy Z, Esiri MM, Jobst KA, Johnston C, Litchfield S, Sim E, Smith AD (1995). Influence of the apolipoprotein e genotype on amyloid deposition and neurofibrillary tangle formation in Alzheimer's disease. Neuroscience, 69: 757-61.

[19] Perl DP (2010). Neuropathology of Alzheimer's disease. Mt Sinai J Med, New York, 77:32-42.

[20] Vagelatos NT, Eslick GD (2013). Type 2 diabetes as a risk factor for Alzheimer's disease: The confounders, interactions, and neuropathology associated with this relationship. Epidemiol Rev, 35:152-60.

[21] Umegaki H (2014). Type 2 diabetes as a risk factor for cognitive impairment: Current insights. Clin Interv Aging, 9:1011-9.

[22] Nasreddine, ZS, Phillips NA, Bedirian V, Charbonneau S, Whitehead V, Collin I, Cummings JL, Chertkow H (2005). The montreal cognitive assessment, MoCA: A brief screening tool for mild cognitive impairment. J Am Geriatr Soc, 53: 695-9.

[23] Luis CA, Keegan AP, Mullan M (2009). Cross validation of the montreal cognitive assessment in community dwelling older adults residing in the southeastern US. Int J Geriatr Psychiatry, 24:197-201.

[24] Lu J, Li D, Li F, Zhou A, Wang F, Zuo X, Jia XF, Song H, Jia J (2011). Montreal cognitive assessment in detecting cognitive impairment in Chinese elderly individuals: A population-based study. J Geriatr Psychiatry Neurol, 24:184-90.

[25] Zhang W, Li Q, Shi L, Lu K, Shang Q, Yao L, Ye G (2009). Investigation of dietary intake of cadmium in certain polluted area of south in china. Wei Sheng Yan Jiu (Chinese), 38:552-4.

[26] Hixson JE, Vernier DT (1990). Restriction isotyping of human apolipoprotein e by gene amplification and cleavage with Hhal. J Lipid Res, 31:545-8.

[27] Friedewald WT, Levy RI, Fredrickson DS (1972). Estimation of the concentration of low-density lipoprotein cholesterol in plasma, without use of the preparative ultracentrifuge. Clin Chem, 18:499-502.

[28] Sheen YJ, Sheu WH (2016). Association between hypoglycemia and dementia in patients with type 2 diabetes. Diabetes Res Clin Pract, 116:279-87.

[29] Umegaki H, Hayashi T, Nomura H, Yanagawa M, Nonogaki Z, Nakshima H, Kuzuya M (2013). Cognitive dysfunction: An emerging concept of a new diabetic complication in the elderly. Geriatr Gerontol Int, 13:2834.

[30] Kouta Y, Sakurai T, Yokono K (2006). Cognitive dysfunction and dementia associated with elderly diabetes. Nihon Rinsho, 64:119-23.

[31] Lee JH, Choi Y, Jun C, Hong YS, Cho HB, Kim JE, Lyoo IK (2014). Neurocognitive changes and their neural correlates in patients with type 2 diabetes mellitus. Endocrinol Metab, 29:112-21.

[32] Wong RH, Scholey A, Howe PR (2014). Assessing premorbid cognitive ability in adults with type 2 diabetes mellitus-a review with implications for future intervention studies. Curr Diab Rep, 14:547.

[33] Ghasemi R, Haeri A, Dargahi L, Mohamed Z, Ahmadiani A (2013). Insulin in the brain: Sources, localization and functions. Mol Neurobiol, 47:145-71.

[34] Wang Y, Xu XY, Feng CH, Li YL, Ge X, Zong GL, Wang YB, Feng B, Zhang P (2015). Patients with type 2 diabetes exhibit cognitive impairment with changes of metabolite concentration in the left hippocampus. Metab Brain Dis, 30:1027-34.

[35] El-Lebedy D, Raslan HM, Mohammed AM (2016). Apolipoprotein e gene polymorphism and risk of type 2 diabetes and cardiovascular disease. Cardiovasc Diabetol, 15:12.

[36] Windler E (2005). What is the consequence of an abnormal lipid profile in patients with type 2 diabetes or the metabolic syndrome? Atheroscler Suppl, 6:11-4.

[37] Taskinen MR (2002). Diabetic dyslipidemia. Atheroscler Suppl, 3: 47-51.

[38] Janson J, Laedtke T, Parisi JE, O'Brien P, Petersen RC, Butler PC (2004). Increased risk of type 2 diabetes in alzheimer disease. Diabetes, 53:474-81.

[39] To AW, Ribe EM, Chuang TT, Schroeder JE, Lovestone S (2011). The epsilon3 and epsilon4 alleles of human apoe differentially affect tau phosphorylation in hyperinsulinemic and pioglitazone treated mice. PloS One, 6:e16991.

[40] Chaudhary R, Likidlilid A, Peerapatdit T, Tresukosol D, Srisuma S, Ratanamaneechat S, Sriratanasathavorn C (2012). Apolipoprotein e gene polymorphism: Effects on plasma lipids and risk of type 2 diabetes and coronary artery disease. Cardiovasc Diabetol, 11:36.

[41] Gomez-Coronado D, Alvarez JJ, Entrala A, Olmos JM, Herrera E, Lasuncion MA (1999). Apolipoprotein e polymorphism in men and women from a spanish population: Allele frequencies and influence on plasma lipids and apolipoproteins. Atherosclerosis, 147:167-76.

[42] Palta P, Schneider AL, Biessels GJ, Touradji P, HillBriggs F (2014). Magnitude of cognitive dysfunction in adults with type 2 diabetes: A meta-analysis of six cognitive domains and the most frequently reported neuropsychological tests within domains. J Int Neuropsychol Soc, 20: 278-91.

[43] Reijmer YD, Brundel M, de Bresser J, Kappelle LJ, Leemans A, Biessels GJ (2013). Microstructural white matter abnormalities and cognitive functioning in type 2 diabetes: A diffusion tensor imaging study. Diabetes care, 36:137-44.

[44] Yeung SE, Fischer AL, Dixon RA (2009). Exploring effects of type 2 diabetes on cognitive functioning in older adults. Neuropsychology, 23:1-9.

[45] Biessels GJ, Strachan MW, Visseren FL, Kappelle LJ, Whitmer RA (2014). Dementia and cognitive decline in type 2 diabetes and prediabetic stages: Towards targeted interventions. Lancet Diabetes Endocrinol, 2:246-55.

[46] Peila R, Rodriguez BL, Launer LJ (2002). Type 2 diabetes, apoe gene, and the risk for dementia and related pathologies: The honolulu-asia aging study. Diabetes, 51:1256-62. 